\title{
Systematics of Alnus maritima (Seaside Alder) Resolved by ISSR Polymorphisms and Morphological Characters
}

\author{
James A. Schrader ${ }^{1}$ and William R. Graves \\ Department of Horticulture, Iowa State University, Ames, IA 50011-1100
}

\begin{abstract}
AdDitional InDEX wORDS. subg. Clethropsis, subspp. oklahomensis and georgiensis, molecular phylogeny, morphometrics, cladistics, inter-simple sequence repeats, fluorescent primers, simultaneous analysis, ABI PRISM, GeneScan

Aвstract. Alnus maritima (Marsh.) Muhl. ex Nutt. is a rare woody plant species that exists as three subspecies found in widely disjunct locations in the United States. Although there is a growing interest in the phytogeography, ecology, conservation, and landscape potential of this species, the phylogeny of $A$. maritima has not yet been resolved by using molecular methods. We have combined a relatively new method of genome fingerprinting, ISSR-PCR, and the automated imaging capabilities of GeneScan technology to investigate the molecular systematics of $A$. maritima. Based on the molecular evidence from 108 ISSR loci, we confirm that the three disjunct populations of $A$. maritima have diverged sufficiently to be classified as subspecies. Our molecular phylogeny of the three subspecies of $A$. maritima agreed in topology with a phylogeny produced from morphological data and showed that subsp. oklahomensis is the most distinct of the three subspecies and was the first to diverge. The simultaneous analysis of molecular and morphological data provides a detailed and balanced phylogeny reconstruction for the three subspecies. Our results support the theory that $A$. maritima originated in Asia, migrated into North America across the Bering land bridge, and was established over a large range in the New World before being forced into its present meager disjunct distribution.
\end{abstract}

Alnus maritima is a rare species of Alnus P. Mill from the subgenus Clethropsis (Spach) Regel. While the other members of subg. Clethropsis, Alnus nepalensis D. Don and Alnus nitida (Spach) Endl., are sympatric and occur in southern Asia, A. maritima is found only in the United States and has a peculiar distribution consisting of three disjunct subspecies separated by $\geq 960 \mathrm{~km}$. Alnus maritima subsp. oklahomensis Schrader \& Graves occurs naturally in only two counties in south-central Oklahoma, A. maritima subsp. georgiensis Schrader \& Graves is isolated to one county in northwestern Georgia, and A. maritima subsp. maritima is found only on the Delmarva Peninsula in four counties in Maryland and two counties in Delaware (Schrader and Graves, 2002).

There are two popular models explaining the phylogeny and phytogeography of A. maritima. Some believe that A. maritima evolved on the Delmarva Peninsula, and that the subspecies in Georgia and Oklahoma were established from Delmarva germplasm by Native Americans or by some natural form of long-distance dispersal (Schrader and Graves, 2002; Stibolt, 1981). Others believe the theory proposed by Furlow (1979), that subg. Clethropsis evolved in southern Asia, that A. maritima diverged from other members of subg. Clethropsis in Asia, and that ancestors of A. maritima migrated into North America via the Bering land bridge and spread across North America before being forced into the present, disjunct range (Furlow, 1979; Schrader and Graves, 2000a, 2002). Some circumstantial evidence supports the possibility of long-distance dispersal of A. maritima by Native Americans (Stibolt, 1981), but most of the evidence, including that from paleobotany, ecology, phylogenetic analyses of morphological characters, and the comparative stress physiology of A. maritima and Clethropsis, supports the second model

Received for publication 11 Feb. 2003. Accepted for publication 22 Oct. 2003 We are grateful to Cynthia Haynes and Jeffery Iles for their helpful critiques of the manuscript.

${ }^{1}$ Corresponding author; e-mail jschrade@iastate.edu.
(Furlow, 1979; Schrader and Graves, 2000a, 2000b, 2002, 2003; Stibolt, 1981). Molecular evidence is needed to complete the systematics of A. maritima, but no studies have been published that utilize molecular approaches to resolve the systematics of this species.

The goals for this study were to determine the molecular phylogenetic relationships among the three subspecies of A. maritima, to measure the divergence and diversity among the three subspecies, and to investigate the origin of the remarkable distribution of A. maritima by using the techniques of molecular systematics. To accomplish these goals we have used the genome fingerprinting methods of inter-simple sequence repeats-polymerase chain reaction (ISSR-PCR) (Zietkiewicz et al., 1994), the automated imaging capabilities of GeneScan technology, and the phylogeny reconstruction tools of the PHYLIP software package (Felsenstein, 1995). We also examined the morphometric phylogeny, assessed cross-matrix disparity (Bateman, 1999), and performed a simultaneous analysis (Nixon and Carpenter, 1996) of morphological and molecular data, producing an infraspecific phylogeny for $A$. maritima that is derived from all the available evidence.

Along with resolving molecular differences at and below the infraspecific level, ISSRs sample a large portion of the genome and therefore avoid the bias accompanying phylogenies based on the sequence of only one or a few genes. Although some researchers object to the use of ISSRs and other PCR-based techniques for phylogenetic analyses because bands of the same size from different genotypes may not be homologous (Harris, 1999), alternative DNA-centered techniques capable of consistently resolving infraspecific variation have not been developed sufficiently (Fang et al., 1997; Wolfe et al., 1998, Wolff and Morgan-Richards, 1999). With randomly amplified polymorphic DNA (RAPD) markers, a technique similar to ISSR-PCR, potential for the occurrence of nonhomologous PCR fragments of the same size increases with genetic distance (Harris, 1999). This problem is considered minimal at the infraspecific level (Wolff and Morgan-Richards, 1999), and it has been demonstrated that $91 \%$ of comigrating products 
Table 1. Vouchers for the 20 individuals sampled for ISSR-PCR analysis. Source abbreviations: (NCRPIS) = North Central Regional Plant Introduction Station, Ames, Iowa; $(\mathrm{S} \& \mathrm{G})=$ Schrader and Graves Alnus collection at Iowa State University. Latitude and longitude are according to Global Positioning System (GPS) and are included when known.

\begin{tabular}{|c|c|c|c|c|c|}
\hline Species or subspecies & Accession & Source & Origin & Latitude & Longitude \\
\hline \multicolumn{6}{|l|}{ A. maritima } \\
\hline \multirow[t]{3}{*}{ subsp. oklahomensis } & OK 4 & $\mathrm{~S} \& \mathrm{G}$ & Connerville, Okla. & $34^{\circ} 20^{\prime} 11.33387^{\prime} \mathrm{N}$ & $96^{\circ} 35^{\prime} 39.47116^{\prime} \mathrm{W}$ \\
\hline & OK 7 & $\mathrm{~S} \& \mathrm{G}$ & Connerville, Okla. & $34^{\circ} 20^{\prime} 11.33387^{\prime} \mathrm{N}$ & $96^{\circ} 35^{\prime} 39.47116^{\prime} \mathrm{W}$ \\
\hline & OK 22 & $\mathrm{~S} \& \mathrm{G}$ & Tishomingo, Okla. & $34^{\circ} 15^{\prime} 38.06^{\prime} \mathrm{N}$ & $96^{\circ} 41^{\prime} 0.67^{\prime} \mathrm{W}$ \\
\hline \multirow[t]{10}{*}{ subsp. georgiensis } & GA 103 & $\mathrm{~S} \& \mathrm{G}$ & Euharlee, Ga. & $34^{\circ} 07^{\prime} 45.09^{\prime} \mathrm{N}$ & $84^{\circ} 56^{\prime} 50.877^{\prime} \mathrm{W}$ \\
\hline & GA 104 & $\mathrm{~S} \& \mathrm{G}$ & Euharlee, Ga. & $34^{\circ} 07^{\prime} 45.09^{\prime} \mathrm{N}$ & $84^{\circ} 56^{\prime} 50.877^{\prime} \mathrm{W}$ \\
\hline & GA 107 & $\mathrm{~S} \& \mathrm{G}$ & Euharlee, Ga. & $34^{\circ} 07^{\prime} 44.48^{\prime} \mathrm{N}$ & $84^{\circ} 56^{\prime} 53.814^{\prime} \mathrm{W}$ \\
\hline & GA 109 & $\mathrm{~S} \& \mathrm{G}$ & Euharlee, Ga. & $34^{\circ} 07^{\prime} 44.48^{\prime} \mathrm{N}$ & $84^{\circ} 56^{\prime} 53.814^{\prime} \mathrm{W}$ \\
\hline & GA 111 & S\&G & Euharlee, Ga. & $34^{\circ} 07^{\prime} 44.48^{\prime} \mathrm{N}$ & $84^{\circ} 56^{\prime} 53.814^{\prime} \mathrm{W}$ \\
\hline & GA 116 & $\mathrm{~S} \& \mathrm{G}$ & Euharlee, Ga. & $34^{\circ} 07^{\prime} 59.12^{\prime} \mathrm{N}$ & $84^{\circ} 57^{\prime} 34.65^{\prime} \mathrm{W}$ \\
\hline & GA 117 & $\mathrm{~S} \& \mathrm{G}$ & Euharlee, Ga. & $34^{\circ} 08^{\prime} 09.99^{\prime} \mathrm{N}$ & $84^{\circ} 57^{\prime} 29.16^{\prime} \mathrm{W}$ \\
\hline & GA 121 & $\mathrm{~S} \& \mathrm{G}$ & Euharlee, Ga. & $34^{\circ} 08^{\prime} 09.99^{\prime} \mathrm{N}$ & $84^{\circ} 57^{\prime} 29.16^{\prime} \mathrm{W}$ \\
\hline & GA 123 & $\mathrm{~S} \& \mathrm{G}$ & Euharlee, Ga. & $34^{\circ} 08^{\prime} 05.69^{\prime} \mathrm{N}$ & $84^{\circ} 57^{\prime} 30.11^{\prime} \mathrm{W}$ \\
\hline & GA 125 & $\mathrm{~S} \& \mathrm{G}$ & Euharlee, Ga. & $34^{\circ} 08^{\prime} 05.69^{\prime} \mathrm{N}$ & $84^{\circ} 57^{\prime} 30.11^{\prime} \mathrm{W}$ \\
\hline \multirow[t]{6}{*}{ subsp. maritima } & MA 205 & $\mathrm{~S} \& \mathrm{G}$ & Snow Hill, Md. & $38^{\circ} 10^{\prime} 06.78774^{\prime} \mathrm{N}$ & $75^{\circ} 26^{\prime} 00.40549^{\prime} \mathrm{W}$ \\
\hline & MA 209 & S\&G & Sharptown, Md. & $38^{\circ} 32^{\prime} 53.358^{\prime} \mathrm{N}$ & $75^{\circ} 43^{\prime} 22.718^{\prime} \mathrm{W}$ \\
\hline & MA 216 & $\mathrm{~S} \& \mathrm{G}$ & Bethel, Del. & $38^{\circ} 36^{\prime} 1.98329^{\prime} \mathrm{N}$ & $75^{\circ} 38^{\prime} 44.40750^{\prime} \mathrm{W}$ \\
\hline & MA 219 & $\mathrm{~S} \& \mathrm{G}$ & Ellendale, Del. & $38^{\circ} 50^{\prime} 13.767^{\prime} \mathrm{N}$ & $75^{\circ} 26^{\prime} 19.466^{\prime} \mathrm{W}$ \\
\hline & MA 221 & $\mathrm{~S} \& \mathrm{G}$ & Ellendale, Del. & $38^{\circ} 50^{\prime} 13.767^{\prime} \mathrm{N}$ & $75^{\circ} 26^{\prime} 19.466^{\prime} \mathrm{W}$ \\
\hline & MA 226 & $\mathrm{~S} \& \mathrm{G}$ & Millsboro, Del. & $38^{\circ} 35^{\prime} 36.96466^{\prime} \mathrm{N}$ & $75^{\circ} 17^{\prime} 27.82579^{\prime} \mathrm{W}$ \\
\hline A. japonica & PI 479297 & NCRPIS & Kushiro-shi, Japan & & \\
\hline
\end{tabular}

are homologous at the species level in the genus Helianthus L. (Rieseberg, 1996). In studies comparing the two techniques, ISSRs were shown to be more reliable and more effective than RAPDs (Moreno et al., 1998; Wolfe et al., 1998), and ISSRs have been used to determine the genetic relationships among species, subspecies, populations, and cultivars of numerous plant taxa (Fang et al., 1998; Huang and Sun, 2000; Iruela et al., 2002; Joshi et al., 2000; Maunder et al., 1999; Potter et al., 2002; Raina, 2001; Wolfe and Randle, 2001). When coupled with other systematic data, such as the morphometric characters utilized in our study, ISSRs can be used to produce strong, consistent phylogenies for plant taxa at or below the interspecific level.

\section{Materials and Methods}

ISSR-PCR techniques (Zietkiewicz et al., 1994) and ABI PRISM GeneScan (Perkin Elmer: Applied Biosystems, Foster City, Calif.) technology were used to fingerprint and compare the genomes of the three subspecies of A. maritima. DNA samples were extracted with CTAB (Doyle and Doyle, 1987) from the roots of greenhouse-grown seedlings (A. maritima) or rooted stem cuttings [Alnus japonica (Thunb.) Steud.]. A total of 20 DNA samples were analyzed, one for A.japonica and 19 for $A$. maritima, which included three for subsp. oklahomensis, 10 for subsp. georgiensis, and six for subsp. maritima (Table 1). After completion of the basic CTAB extraction, all DNA samples were purified further with GENECLEAN (Qbiogene, Inc., Carlsbad, Calif.).

DNA samples were amplified for three replications with each of three fluorescent 3 '-anchored ISSR primers $\left[(\mathrm{CA})_{6} \mathrm{RG},(\mathrm{AC})_{8} \mathrm{G}\right.$, and $\left.(\mathrm{AG})_{8} \mathrm{YT}\right]$, which were synthesized at the DNA Sequencing and Synthesis Facility at Iowa State University. These primer sequences were chosen based on their successful use with other woody plant species (Fang et al., 1997; Fang et al., 1998; Moreno et al., 1998; Tsumara et al., 1996). Optimization reactions under the range of conditions employed by recent authors were run to determine proper reaction conditions and reagent concentrations for consistent PCR amplification. Thermocycler conditions for ISSR-PCR were $94^{\circ} \mathrm{C}$ for $5 \mathrm{~min}$ (initial denaturing), $94^{\circ} \mathrm{C}$ for 30 $\mathrm{s}$ (denaturing), primer-specific temperatures (see below) for $45 \mathrm{~s}$ (annealing), and $72{ }^{\circ} \mathrm{C}$ for $2 \mathrm{~min}$ (extension), for 30 cycles with the final extension at $72^{\circ} \mathrm{C}$ for $5 \mathrm{~min}$. Annealing temperatures for the three primers were $47^{\circ} \mathrm{C}$ for $(\mathrm{CA})_{6} \mathrm{RG}, 50^{\circ} \mathrm{C}$ for $(\mathrm{AC})_{8} \mathrm{G}$, and $54{ }^{\circ} \mathrm{C}$ for $(\mathrm{AG})_{8} \mathrm{YT}$. In our $25-\mu \mathrm{L}$ reaction mixes, we used $30 \mathrm{ng}$ of template DNA, $1.2 \mu \mathrm{M}$ of primer, $300 \mu \mathrm{M}$ dNTP mix (SIGMA, St. Louis, Mo.), $1 \times$ reaction buffer containing $\mathrm{Mg}(\mathrm{OAc})_{2}$, and 1.5 units of KlenTaq LA DNA polymerase (SIGMA).

Amplification products were processed at the DNA Sequencing and Synthesis Facility at Iowa State University. Applied Biosystems (ABI) 377 automated DNA sequencing systems separated the DNA by electrophoresis and collected the gel image (Fig. 1). Image data were analyzed by using the facility's ABI PRISM GeneScan software that accurately resolves DNA fragment length differences as small as one base pair. ISSR bands (loci) were scored as 1 for band presence and 0 for band absence. Only bands that appeared in at least two of the three replications were considered present. A locus was any fragment length that was present in at least one sample for a given taxonomic level. The resulting two-state (1 $\bullet$ 0 ) data matrices for the three primers were combined to form a cumulative data set for assessing molecular relationships among and within the three subspecies of A. maritima.

The UPGMA analysis of all individuals was performed by using JMP software (SAS Institute Inc., Cary, N.C.). Cladistic and phenetic analyses were performed by using PHYLIP (Phylogeny Inference Package; Felsenstein, 1995). The Seqboot program was used for bootstrap (Felsenstein, 1985) and jacknife (Farris et al., 1996) analyses, the Mix program for Wagner parsimony analysis, the Consense program for consensus trees, and the Neighbor program for neighbor-joining dendrograms (Felsenstein, 1995). Genetic distances for neighbor-joining analyses were Euclidean distances (Sneath and Sokal, 1973). We compared and contrasted our morphometric and molecular phylogenies, a procedure termed 


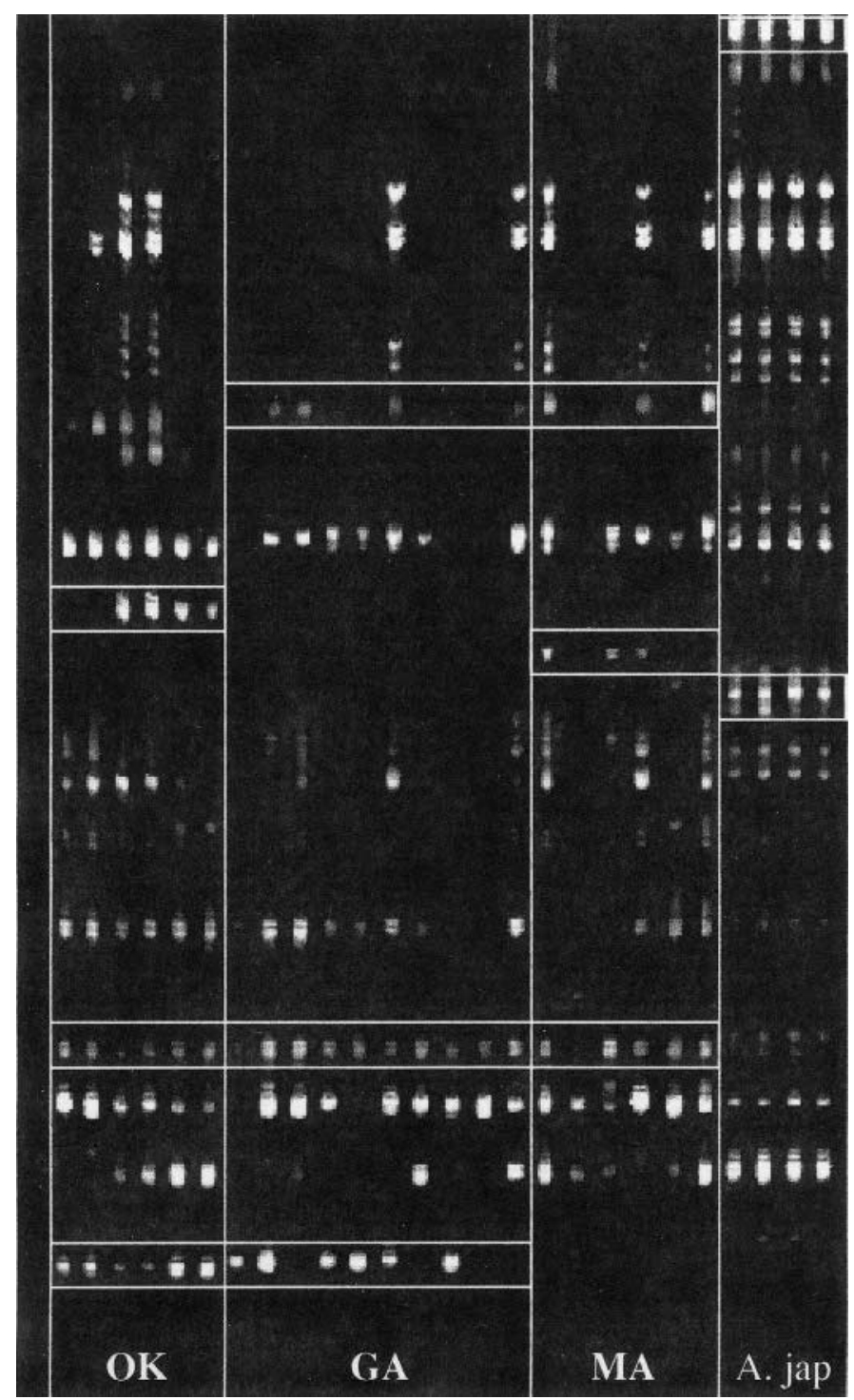

Fig. 1. Gel image produced by GeneScan and showing banding patterns from ISSR-PCR (inter-simple sequence repeats-polymerase chain reaction) of total DNA from four Alnus taxa. Lanes are shown divided into groups reading from left to right: A. maritima subsp. oklahomensis (OK), subsp. georgiensis (GA), subsp. maritima (MA), and A. japonica (A. jap). Some taxon-specific bands and bands shared by only two of the subspecies have been highlighted with boxes. Primer for this run was a fluorescent-labeled, $3^{\prime}$-anchored simple sequence repeat $\left[(\mathrm{CA})_{6} \mathrm{RG}\right]$. This figure may be viewed in color at http: //www.hort.iastate.edu/graves/.

cross-matrix disparity by Bateman (1999), then merged the two data sets for a simultaneous analysis (Nixon and Carpenter, 1996). Morphological data were standardized, unweighted, and derived from the measurements of Schrader and Graves (2002). Alnus japonica was chosen as the outgroup for cladistic analyses because it is considered to be monophyletic with A. maritima and is a member of the most primitive section of Alnus (Furlow, 1979).

\section{Results}

ISSR-PCR produced ample molecular markers for assessing the variability and phylogenetic relationships among the subspecies of $A$. maritima. ISSR banding patterns were clearly resolved with the ABI 377 automated sequencing system, and allele calling was easily accomplished with GeneScan software
(Fig. 1). Using three primers, our amplifications produced 108 bands (loci) total. Abundant polymorphisms and taxon-specific markers (Table 2) illustrated the resolving power of ISSR-PCR and the three chosen primers. UPGMA analysis of banding patterns from all samples placed all individuals within the cluster of their subspecies (Fig. 2).

An exhaustive search produced a single most parsimonious tree of 89 steps for the molecular relationship among the three subspecies of A. maritima. Bootstrap and jacknife frequencies for the molecular phylogeny (Fig. 3I) were $92 \%$ and $90 \%$, respectively, for the clade of subspp. georgiensis and maritima, values that strongly support this topology. Molecular and morphometric analyses produced trees with the same topology (Fig. 3I and II). Both phylogenies show subsp. oklahomensis diverging first, followed by the divergence of the two subspecies from the eastern United States, subspp. georgiensis and maritima. Although the branch lengths for the molecular and morphometric phylogenies were not identical, comparison of the two trees show them to be similar and proportional (Figs. 3I and II). Simultaneous analysis of the combined molecular and morphological data (Fig. 4) again gave the same topology and provided reasonable adjustments in branch lengths, balancing the phenotypic and genotypic information concerning the subspecies.

Euclidean distances between subspecies given by molecular data were 15 for oklahomensis to georgiensis, 19 for oklahomensis to maritima, and 12 for georgiensis to maritima. Euclidean distances between subspecies given by unweighted morphological data were 15.2 for oklahomensis to georgiensis, 18.1 for oklahomensis to maritima, and 10.3 for georgiensis to maritima. The total Euclidean distances between subspecies given by simultaneous analysis were 30.2 for oklahomensis to georgiensis, 37.1 for oklahomensis to maritima, and 22.3 for georgiensis to maritima. These pairwise comparisons indicate that, even though subsp. oklahomensis is not the most derived, it is the most unique of the three subspecies at both the molecular and morphological levels.

\section{Discussion}

The parallel topology of the morphometric and molecular phylogenies of the three subspecies of A. maritima (Fig. 3I and 3II) provides strong evidence supporting the classification and systematics of these taxa described by Schrader and Graves (2002). The striking similarity between the trees in both topology and branch length illustrates the effectiveness of the morphometric and ISSR characters for estimating the phylogenetic history of these subspecies. In addition to these parallel phylogenies, the UPGMAclustering of all individuals within their subspecies (Fig. 2 ) and the discovery of taxon-specific markers at the subspecies level (Table 2, Fig. 1) provide strong molecular evidence that the three disjunct populations of $A$. maritima have differentiated sufficiently to be considered separate subspecies.

Along with demonstrating that subsp. oklahomensis was the first of the subspecies to diverge, all three dendrograms also show a relatively short branch for the line leading to subsp. georgiensis, indicating a lesser degree of differentiation for subsp. georgiensis after divergence than the differentiation for the other two subspecies. Another indication that subsp. georgiensis has undergone less differentiation than the other two subspecies is its lower number of subspecies-specific markers (three compared to four and six for subspp. oklahomensis and maritima, respectively) shown in the ISSR analysis (Table 2). 
Table 2. Percentage of polymorphic loci among and within the three subspecies of $A$. maritima and taxon-specific bands resolved by using three, 3'-anchored ISSR primers.

\begin{tabular}{|c|c|c|c|c|}
\hline & \multicolumn{4}{|c|}{ Primer } \\
\hline & $(\mathrm{CA})_{6} \mathrm{RG}$ & $(\mathrm{AG})_{8} \mathrm{YT}$ & $(\mathrm{AC})_{8} \mathrm{G}$ & All three primers \\
\hline \multicolumn{5}{|l|}{ \% of polymorphic loci } \\
\hline Totalz & 81 & 75 & 86 & 80 \\
\hline Among subspecies & 41 & 55 & 46 & 48 \\
\hline within oklahomensis & 16 & 25 & 17 & 20 \\
\hline within georgiensis ${ }^{\mathrm{y}}$ & 17 & 9 & 39 & 20 \\
\hline within maritima & 30 & 22 & 23 & 25 \\
\hline \multicolumn{5}{|l|}{ Taxon-specific loci } \\
\hline subsp. oklahomensis & 1 & 3 & 0 & 4 \\
\hline subsp. georgiensis & 0 & 1 & 2 & 3 \\
\hline subsp. maritima & 2 & 4 & 0 & 6 \\
\hline A. japonica & 9 & 16 & 12 & 37 \\
\hline
\end{tabular}

zValues include loci for A. japonica.

yTo achieve a consistent comparison among subspecies, polymorpic loci for subspp. georgiensis and maritima were determined for three randomly chosen samples each.

The conclusion that subsp. oklahomensis is the most unique of the subspecies is reasonable because it was the first of the subspecies to diverge and has therefore been isolated from subspp. georgiensis and maritima longer than these two subspecies have been isolated from each other. Another factor that may have contributed to the unique character of subsp. oklahomensis could be the uniqueness of its environmental niche. Plants of subsp. oklahomensis grow in and along swiftly flowing rivers and streams, while plants of the other two subspecies inhabit ponds or slow-flowing waterways. Soil potassium, calcium, and

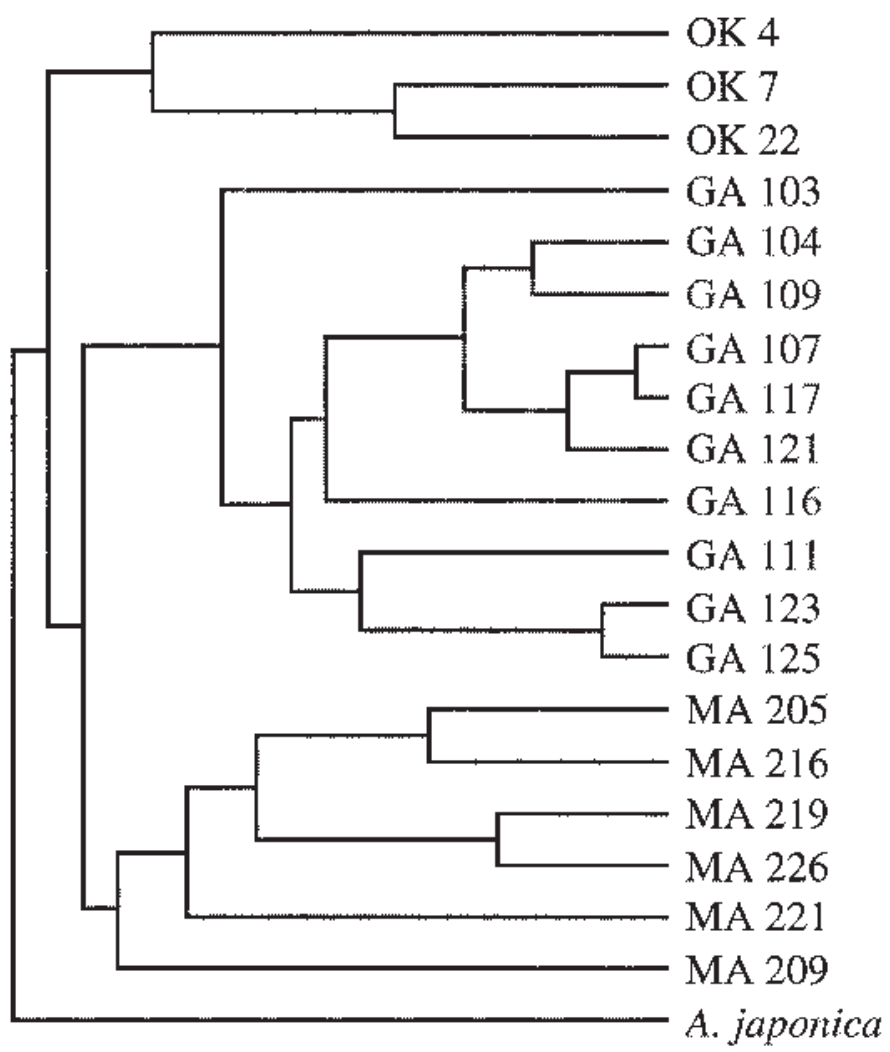

Fig. 2. UPGMA dendrogram characterizing the molecular relationship among all 20 individuals sampled and illustrating the resolving power of the three intersimple sequence repeats (ISSR) primers. This figure may be viewed in color at http://www.hort.iastate.edu/graves/. magnesium concentrations of the Oklahoma provenance are over twice those of the other two provenances, and soil $\mathrm{pH}$ in the Oklahoma habitat is alkaline, while the $\mathrm{pH}$ of the other two habitats is acid (Schrader and Graves, 2002). The Oklahoma provenance also has the warmest winter and hottest summer temperatures of the three locations. Its early isolation and adaptation to the most unique niche of the three subspecies probably have contributed to the unique character of subsp. oklahomensis.

While ISSR fingerprinting showed clear differentiation between the three subspecies, the methods were also sensitive enough to detect diversity within each subspecies. Of the loci detected for each subspecies individually, $20 \%, 20 \%$, and $25 \%$ were polymorphic for subspp. oklahomensis, georgiensis, and maritima, respectively, across all three primers (Table 2). This substantial degree of ISSR polymorphism reinforces the morphological findings of Schrader and Graves (2002) that sufficient genetic diversity exists within each subspecies and that the degree of genetic diversity should not be a hindrance to the long-term survival of the three subspecies.

Our molecular phylogeny of A. maritima provides further support for Furlow's model of divergence and migration, while almost directly opposing the other model, that A. maritima originated on the Delmarva Peninsula and underwent long-distance dispersal to the other two locations. This new evidence, appearing in its most complete form in the simultaneous analysis (Fig. 4), confirms that subsp. oklahomensis was the first of the three subspecies to diverge and that subsp. maritima is the most derived of the subspecies, rather than the most primitive.

There is a growing interest in the use of A. maritima as an ornamental for managed landscapes (Schrader and Graves, 2000a), and the first cultivar was recently selected (Graves and Schrader, 2004). Because of the disjunct distribution of A. maritima, the subspecies have already differentiated sufficiently to provide genotypic resources on which to begin plant-breeding efforts. Our discovery of subspecies-specific ISSR markers and detection of polymorphisms within each subspecies indicate that ISSRs could be a valuable tool for breeding of this species. If desired characteristics could be linked to specific ISSR markers, plants would not have to reach full maturity, potentially several years, to screen for successful crosses. Alnus maritima can flower within two to three years, but requires about 10 years to attain full size. ISSR markers could facilitate the sequential crossing of plants in a fraction of the time that would otherwise be required. 

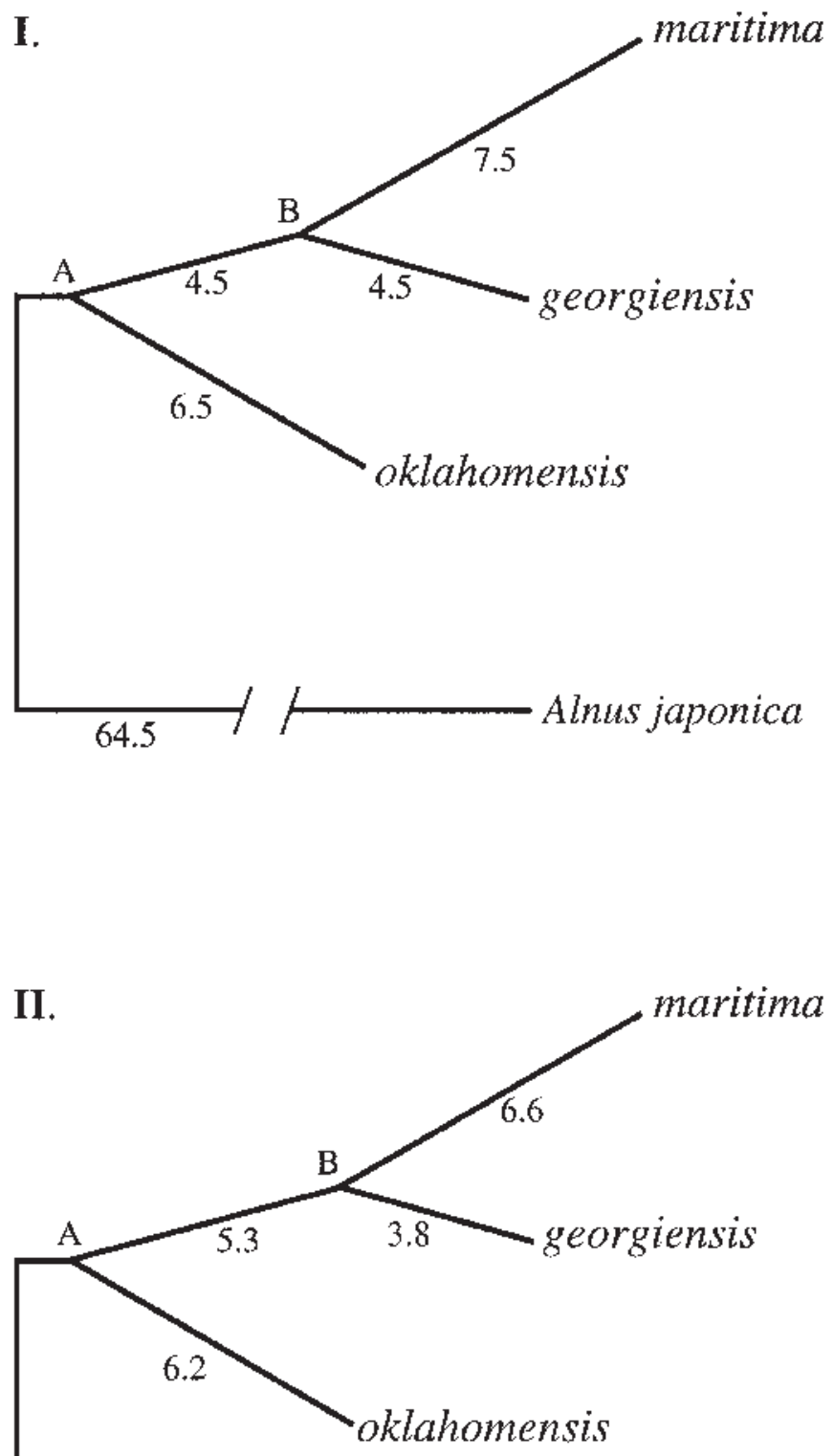

64.3

Alnus japonica

Fig. 3. (I) The single most parsimonious tree of 89 steps characterizing the inferred phylogenetic relationship among the three subspecies of Alnus maritima based on molecular data (polymorphisms in 108 ISSR [inter-simple sequence repeats] loci total). Bootstrap and jacknife percentages for clade B were 92 and 90, respectively, based on 1000 resamplings each. (II) Inferred phylogeny for the three subspecies of Alnus maritima based on unweighted morphological data ( 23 characters), derived from the measurements of Schrader and Graves (2002). Alnus japonica, an Asian species from a primitive section of subg. Alnus (Furlow, 1979), was designated as the outgroup for both cladograms. Numbers indicate the branch lengths from a point of divergence to the position of an extant taxon or the distance between successive points of divergence (A to B). Euclidean distances between subspecies given by molecular data were 15 for oklahomensis to georgiensis, 19 for oklahomensis to maritima, and 12 for georgiensis to maritima. Euclidean distances between subspecies given by unweighted morphological data were 15.2 for oklahomensis to georgiensis, 18.1 for oklahomensis to maritima, and 10.3 for georgiensis to maritima. Both phylogenies were produced using the neighbor-joining algorithm of PHYLIP (Phylogeny Inference Package; Felsenstein, 1995).

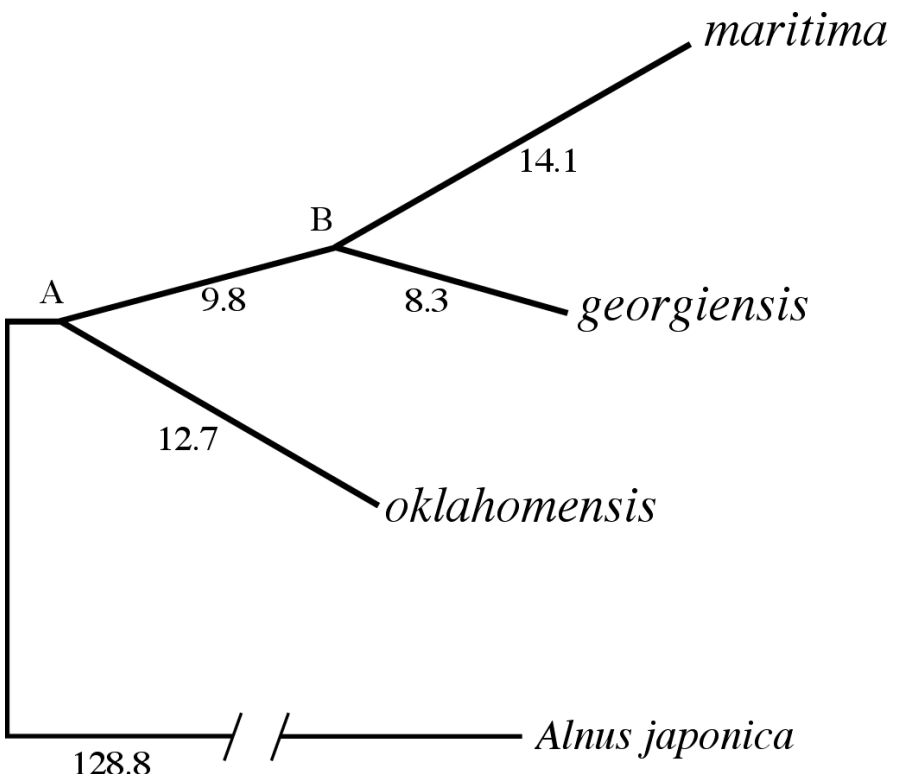

Fig. 4. Inferred phylogenetic relationship among the three subspecies of Alnus maritima based on the simultaneous analysis (Nixon and Carpenter, 1996) of inter-simple sequence repeats (ISSR) polymorphisms together with 23 characters of morphology derived from the results of Schrader and Graves (2002). Molecular and morphological data were unweighted and analyzed by using Euclidean distances and the neighbor-joining method. Alnus japonica was the designated outgroup. Numbers indicate the branch lengths from a point of divergence to the position of an extant taxon or the distance between successive points of divergence (A to B). The total Euclidean distances between subspecies were 30.2 for oklahomensis to georgiensis, 37.1 for oklahomensis to maritima, and 22.3 for georgiensis to maritima.

\section{Literature Cited}

Bateman, R.M. 1999. Integrating molecular and morphological evidence of evolutionary radiations, p. 432-471. In: P.M. Hollingsworth, R.M. Bateman, and R.J. Gornall (eds.). Molecular systematics and plant evolution. Taylor and Francis, London.

Doyle, J.J. and J.L. Doyle. 1987. A rapid DNA isolation procedure for small quantities of fresh leaf tissue. Phytochem. Bull. Bot. Soc. Amer. 19:11-15.

Fang, D.Q., M.L. Roose, R.R. Krueger, and C.T. Federici. 1997. Fingerprinting trifoliate orange germplasm accessions with isozymes, RFLPs, and inter-simple sequence repeat markers. Theor. Appl. Genet. 95:211-219.

Fang, D., R.R. Krueger, and M.L. Roose. 1998. Phylogenetic relationships among selected Citrus germplasm accessions revealed by intersimple sequence repeat (ISSR) markers. J. Amer. Soc. Hort. Sci. 123: 612-617.

Farris, J.S., V.A. Albert, M. Källersjö, D. Lipscomb, and A.G. Kluge. 1996. Parsimony jacknifing outperforms neighbor-joining. Cladistics 12:99-124.

Felsenstein, J. 1985. Confidence limits on phylogenies: an approach using the bootstrap. Evolution 39:783-791.

Felsenstein, J. 1995. PHYLIP (Phylogeny Inference Package) Version $3.57 \mathrm{c}$. Distributed by the author. Department of Genetics, University of Washington, Seattle.

Furlow, J.J. 1979. The systematics of the American species of Alnus (Betulaceae). Rhodora 81:1-121, 151-248.

Graves, W.R. and J.A. Schrader. 2004. 'September Sun' seaside alder, an autumn-blooming shrub native to North America. HortScience (in press).

Harris, S.A. 1999. RAPDs in systematics: A useful methodology? p. 211-228. In: P. M. Hollingsworth, R. M. Bateman, and R. J. Gornall, (eds.). Molecular systematics and plant evolution. Taylor and Francis, London. 
Huang, J.C. and M. Sun. 2000. Genetic diversity and relationships of sweetpotato and its wild relatives in Ipomoea series Batatas (Convolvulaceae) as revealed by inter-simple sequence repeat (ISSR) and restriction analysis of chloroplast DNA. Theor. Appl. Genet. 100: 1050-1060.

Iruela, M., J. Rubio, J.I. Cubero, J. Gil, and T. Millán. 2002. Phylogenetic analysis in the genus Cicer and cultivated chickpea using RAPD and ISSR markers. Theor. Appl. Genet. 104:643-651.

Joshi, S.P., V.S. Gupta, R.K. Aggarwal, P.K. Ranjekar, and D.S. Brar. 2000. Genetic diversity and phylogenetic relationship as revealed by inter simple sequence repeat (ISSR) polymorphism in the genus Oryza. Theor. Appl. Genet. 100:1311-1320.

Maunder, M., A. Culham, A. Bordeu, J. Allainguillaume, and M. Wilkinson. 1999. Genetic diversity and pedigree for Sophora toromiro (Leguminosae): a tree extinct in the wild. Mol. Ecol. 8:725-738.

Moreno, S., J.P. Martin, and J.M. Ortiz. 1998. Inter-simple sequence repeats PCR for characterization of closely related grapevine germplasm. Euphytica 101:117-125.

Nixon, K.C. and J.M. Carpenter. 1996. On simultaneous analysis. Cladistics 12:221-241.

Potter, D., G. Fangyou, G. Aiello, C. Leslie, and G. McGranahan. 2002. Intersimple sequence repeat markers for fingerprinting and determining genetic relationships of walnut (Juglans regia) cultivars. J. Amer. Soc. Hort. Sci. 127:75-81.

Raina, S.N. 2001. RAPD and ISSR fingerprints as useful genetic markers for analysis of genetic diversity, varietal identification, and phylogenetic relationships in peanut (Arachis hypogaea) cultivars and wild species. Genome 44:763-772.

Rieseberg, L.H. 1996. Homology among RAPD fragments in interspecific comparisons. Mol. Ecol. 5:99-105.

Schrader, J.A. and W.R. Graves. 2000a. Alnus maritima: a rare woody species from the New World. The New Plantsman 7:74-82.
Schrader, J.A. and W.R. Graves. 2000b. Seed germination and seedling growth of Alnus maritima from its three disjunct populations. J. Amer. Soc. Hort. Sci. 125:128-134.

Schrader, J.A. and W.R. Graves. 2002. Infraspecific systematics of $A l$ nus maritima (Betulaceae) from three widely disjunct provenances. Castanea 67:380-401.

Schrader, J.A. and W.R. Graves. 2003. Phenology and depth of cold acclimation in the three subspecies of Alnus maritima. J. Amer. Soc. Hort. Sci. 128:330-336.

Sneath, P.H. and R.R. Sokal. 1973. Numerical taxonomy. W.H. Freeman and Co., San Francisco.

Stibolt, V.M. 1981. The distribution of Alnus maritima Muhl. ex Nutt. (Betulaceae). Castanea 46:195-200.

Tsumara, Y., K. Ohba, and S.H. Strauss. 1996. Diversity and inheritance of inter-simple sequence repeat polymorphisms in douglas-fir (Pseudotsuga menziesii) and sugi (Cryptomeria japonica). Theor. Appl. Genet. 92:40-45.

Wolfe, A.D. and C.P. Randle. 2001. Relationships within and among species of the holoparasitic genus Hyobanche (Orobanchaceae) inferred from ISSR banding patterns and nucleotide sequences. Systematic Bot. 26:120-130.

Wolfe, A.D., Q. Xiang, and S.R. Kephart. 1998. Assessing hybridization in natural populations of Penstemon (Scrophulariaceae) using hypervariable intersimple sequence repeat (ISSR) bands. Mol. Ecol. 7:1107-1125.

Wolff, K. and M. Morgan-Richards. 1999. The use of RAPD data in the analysis of population genetic structure: case studies of Alkanna (Boraginaceae) and Plantago (Plantaginaceae), p. 51-73. In: P.M. Hollingsworth, R.M. Bateman, and R.J. Gornall (eds.). Molecular systematics and plant evolution. Taylor and Francis, London.

Zietkiewicz, E.,A. Rafalski, and D. Labuda. 1994. Genome fingerprinting by simple sequence repeat (SSR)-anchored polymerase chain reaction amplification. Genomics 20:176-183. 